\title{
A New Method for Quantifying Fire Growth Rates Using Statistical and Empirical Data - Applied to Determine the Effect of Arson
}

\author{
MARTIN NILSSON, NILS JOHANSSON and PATRICK VAN HEES \\ Department of Fire Safety Engineering and Systems Safety \\ Lund University, P.O. Box 118, SE-221 00 Lund, Sweden, Telephone: +46 462227360
}

\begin{abstract}
When designing fire safety of buildings the fire growth rate is an important parameter, in large affecting the overall fire safety level within the building. Generally, a deterministic fire growth rate is used raising the question whether the resulting design arrives at a reasonable level of safety. A method was developed to obtain distributions of fire growth rates in specific building types. The new method uses data from two sources: fire statistics, and fire growth rates on single objects obtained by calorimetry experiments. In addition, the method was demonstrated by a case study investigating whether the overall fire growth rate is faster for commercial buildings if arson fires are included than if they are not. The results show that there is a considerably higher fire growth rate when arson fires are accounted for, e.g. designing for a fast fire growth rate of $0.047 \mathrm{~kW} / \mathrm{s}^{2}$ covers $97 \%$ of accidental fires (arson excluded) but only $91 \%$ of all fires (arson included). The results indicate that there is a need to account for arson fires when designing buildings when the probability of arson is high. The developed method provides means to account for arson in fire safety engineering, and to further quantify the achieved fire safety level.
\end{abstract}

KEYWORDS: fire growth, statistics, building code, design fire, fire safety engineering

\section{INTRODUCTION}

A common approach in fire safety engineering, and design of buildings, is to determine a design fire where the heat release rate (HRR) is described with an exponential fire growth rate for the pre-flashover phase [1]. This in turn forms the basis of the design. The exponential fire growth rate is often referred to as the alpha$\mathrm{t}^{2}$ fire curve, and it is described in textbooks and guidelines used for fire safety engineering, see Eq. 1.

$\dot{Q}=\alpha \cdot t^{2}$

In Eq. $1, \dot{Q}$ is the HRR (kW), $\alpha$ is the fire growth rate $\left(\mathrm{kW} / \mathrm{s}^{2}\right)$ and $t$ is the time (s). A faster burning fuel will generally have a higher alpha-value, i.e. a faster fire growth rate, and approximate alpha-values for a range of different objects (i.e. fuel packages) are available in the literature [1]. Due to limited resources, it is not possible to analyse more than a very limited amount of possible fire scenarios during the design phase of a building. The resulting fire safety level is dependent upon a large variety of parameters, e.g. maximum HRR, production of smoke and soot, fire growth rate etc. In the early stage of a fire, the fire growth rate is probably the most important parameter for life safety. Consequently, the resulting safety level is highly dependent upon the choice of the fire growth rate, which in turn determines the HRR, previously expressed to be the most important variable in fire hazards [2]. Lately some building codes have prescribed fire growth rates, for different occupancies, to be used in performance based design $[3,4]$. In general, this choice of a deterministic fire growth rate for design is thought to represent the worst possible conditions that could "reasonably" occur, often called the worst-credible case. This can be compared to treating uncertainties on level 2 according to Paté-Cornell [5], on level 2 uncertainties are treated by choosing conservative values. However deciding on what value of fire growth rate to be used for design is often problematic and, as Paté-Cornell [5] points out, there is always the question of how conservative the chosen value actually is. Since the uncertainties, or the risks, are not quantified, the worst-credible case approach presents shortcomings in the risk management phase since it does not allow for meaningful comparisons of risks and therefore priorities between mitigating measures are difficult [5].

A faster fire growth rate can be associated with a shorter available safe egress time (ASET) causing the required safe egress time (RSET) to be longer than ASET, hence endangering people [6]. In addition to the increased threat to life safety a faster fire growth rate could result in less time for the fire service to 
intervene, which could affect life safety as well as property damage. A faster growing fire than designed for could also result in impairment of fire protection systems. As an example, a sprinkler system might not be able to control the fire if the fire is too large upon activation, smoke management system might be overwhelmed causing large property damage and a negative effect on life safety. Therefore, it is desirable to find the actual distribution of fire growth rates for different types of buildings, in order to quantify how conservative the chosen fire growth rate actually is. Furthermore, with a distribution of the fire growth rate the design can be made towards a well-defined target, e.g. the building should be designed to be able to handle $98 \%$ of all possible fires.

Most buildings codes have a focus on life safety in case of accidental fires, i.e. fires that starts by accident, or rather; there is no explicit approach to deal with antagonistic threats such as arson. This is of course reasonable if there is no significant difference between the fire growth rate of only accidental fires and all fires (including arson). Arson is a common cause of fires according to statistics from several countries, e.g. in Sweden and UK arson accounts for $10-15 \%$ and $15-20 \%$ respectively of all fires in buildings [7, 8]. However, the extent of arson also varies with the type of occupancy and in Sweden, for example, arson accounts for $8 \%$ of fires in residential buildings and for more than $40 \%$ of fires in school buildings. In many cases arson accounts for a large part of all fires, and it might be important to give special attention to these fires in fire safety design of buildings.

Typical arson fire scenarios in schools have been identified in a previous study [9] but there was no detailed analysis conducted whether these scenarios had a faster fire growth rate than accidental fires. Holborn et al [10] used the Real Fire Library, a database consisting of data collected by the London Fire Brigade investigators, to among other things find lognormal distributions for fire growth rates for use in probabilistic fire risk assessments. According to Holborn et al (see table 1) a fire with an alpha-value of $0.047 \mathrm{~kW} / \mathrm{s}^{2}$ will cover $95 \%$ of all fires in public buildings and $89 \%$ of all fires in retail (including arson fires). Nystedt [11] has also tried to quantify distributions of the fire growth rate in retail buildings with the conclusion that the $92^{\text {nd }}$ percentile corresponds to a fire growth rate of $0.047 \mathrm{~kW} / \mathrm{s}^{2}$. However, no study of how the fire cause (e.g. arson) affects the fire growth rate was conducted in the studies. Furthermore, Holborn's [10] data is limited to buildings in London and conditions there might not apply to other countries because of differences in construction, regulations, culture etc. Nystedt's [11] data used fire growth rates for upholstered furniture [12]; hence the results only apply to furniture while the combustibles in e.g. a retail store can be different. Angerd and Frantzich [13] also tried obtaining a fire growth rate distribution by conducting an inventory of combustible material in 15 retail stores. The data, however, was limited and only resulted in a discrete distribution.

Table 1. Parameters for lognormal distributions and percentile values according to Holborn et al [10].

\begin{tabular}{|l|c|c|c|c|c|c|}
\cline { 2 - 6 } \multicolumn{1}{c|}{} & $\boldsymbol{\mu}_{\boldsymbol{\alpha}}$ & $\boldsymbol{\sigma}_{\boldsymbol{\alpha}}$ & $\begin{array}{c}\mathbf{E}(\boldsymbol{\alpha}) \\
\left(\mathbf{k W} / \mathbf{s}^{2}\right)\end{array}$ & $\begin{array}{c}\boldsymbol{\alpha}_{\mathbf{9 5}} \\
\left(\mathbf{k W} / \mathbf{s}^{2}\right)\end{array}$ & $\begin{array}{c}\boldsymbol{\alpha}_{\mathbf{9 9 . 5}} \\
\left(\mathbf{k W} / \mathbf{s}^{\mathbf{2}}\right)\end{array}$ & $\begin{array}{c}\text { Percentile for } \boldsymbol{\alpha} \\
=\mathbf{0 . 0 4 7} \mathbf{~ k W / \mathbf { s } ^ { 2 }}\end{array}$ \\
\hline $\begin{array}{l}\text { Holborn (public } \\
\text { buildings, N=10) }\end{array}$ & -6.2 & 1.9 & 0.012 & 0.0463 & 0.2711 & $95 \%$ \\
\hline $\begin{array}{l}\text { Holborn (retail, } \\
\mathbf{N}=\mathbf{3 7 )}\end{array}$ & -5.4 & 1.9 & 0.0275 & 0.1031 & 0.6046 & $89 \%$ \\
\hline
\end{tabular}

The fire growth rate is one of the most important parameters in fire safety engineering affecting the fire safety level of a building. Often a deterministic fire growth rate is chosen for design and there is no quantification of the severity of the chosen value, hence resulting in an unknown safety level. Furthermore the effect of more severe fire scenarios such as arson might need to be accounted for if they affect the overall fire growth rate. The aim of this paper is to develop a method to obtain distributions of fire growth rates in specific building types with the ability to differentiate between different fire causes, hence enabling quantification of the severity of the chosen fire growth rate. Furthermore, the aim is to use the method to investigate whether the overall fire growth rate is faster for commercial buildings (buildings containing retail e.g. shopping centres) if arson fires are included than if they are not. Since the fire growth rate impacts the overall safety level in the building it is believed that arson fires need special attention in building design. Especially in multifunctional and public buildings, like shopping malls, where the occupant density can be high, important societal functions can be gathered and the probability of arson fires occurring could be fairly high [14]. 


\section{METHOD AND CASE STUDY FOR COMMERCIAL BUILDINGS}

To assess the effect of different fire causes on the fire growth rate it is necessary to develop a new method that has its origin in fire statistics that differentiate between fire causes. This was not possible with the previous mentioned studies [10, 11, 13] as the results are presented. In Sweden, the Swedish Civil Contingencies Agency (MSB) has gathered statistics from all rescue service operations since 1996 [8]. More than 150,000 incidents where the rescue service has responded to a fire in a building are included in this extensive database. The statistics can be used to make analyses of a range of different parameters. However, the database does not hold any information on fire growth or fire size at certain time points, as the data used by Holborn et al [10] did. Consequently, the MSB statistics alone cannot be used to determine distributions of the fire growth rates in Swedish buildings. Therefore, the new method needs to include other sources of data.

Firstly, the statistics from MSB were examined in order to determine the possible ways of using the data to obtain distributions for the fire growth rates. It was concluded that the statistics from MSB needed to be complemented with experimental data on fire growth rates for single burning objects. The principle of the method is shown in Fig. 1. In certain building types there are a number of recorded fires with recorded first objects ignited. By determining the fire growth rates for all recorded first objects ignited and grouping the fires where the fire growth rate falls in a certain interval a histogram is obtained. The histogram essentially is a discrete distribution to which a continuous distribution can be fitted. The practical working procedure in Fig. 1 is starting from the right and works further to the left. Each object ignited has been assigned a fire growth rate and each fire has a first object ignited and therefore the fire growth rates have a frequency creating the distribution for the building type.

For some of the objects it was difficult to determine a fire growth rate due to imprecise labeling of first objects ignited in the statistical data. The imprecise labels were "other", "unknown", "furnishing and decorations", "other furnishing and decorations". In order to obtain more representative fire growth rates for these labels, the room type was used to be able to pinpoint likely fire growth rates, i.e. an "unknown" fire in a kitchen will likely be different from an "unknown" fire in a sales area. The values for "furnishing and decorations" and "other furnishing and decorations" were chosen based on the room type and what type of combustibles that are expected to be present in the room type. The objects "other" and "unknown" on the other hand were given a fire growth rate that is a weighted average value for each room type, i.e. when the object is unknown it is assumed to have a fire growth rate that is distributed according to the other objects in that room type. This is considered to give a better estimate than if an overall average of fire growth rate in the building was used. Also see Appendix A for further information.

These procedures constitute the method itself and then a case study was done for Swedish commercial buildings to find the distributions for all fires (including arson) and accidental fires (excluding arson). 


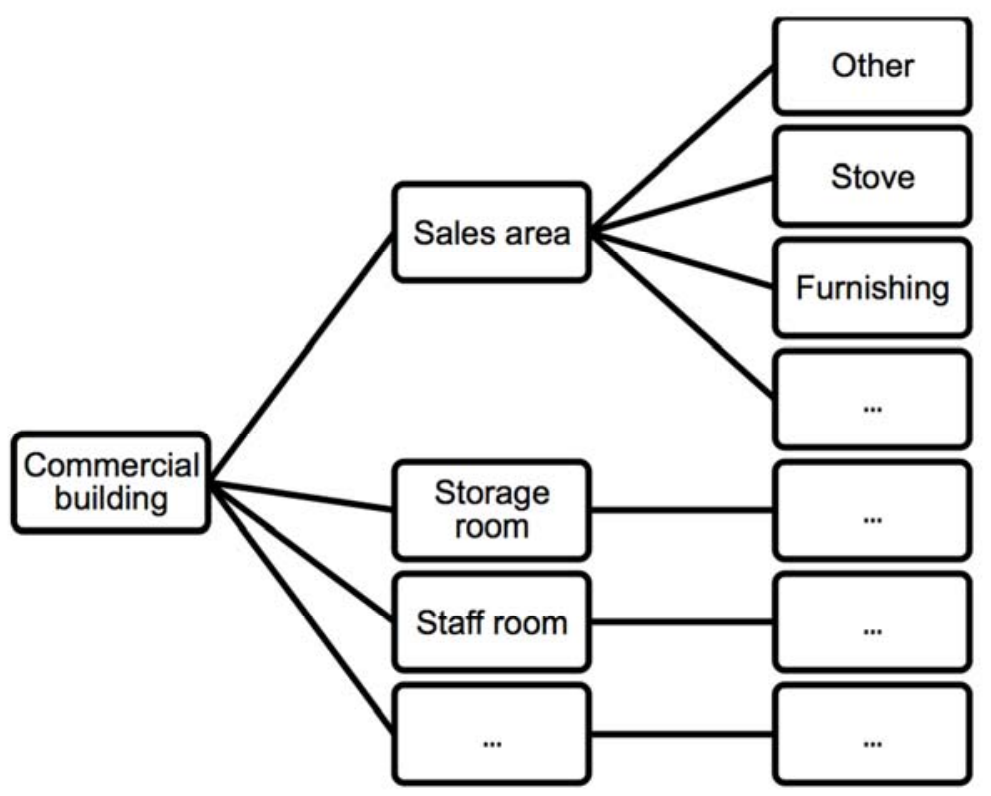

Fig. 1. The fires are categorized with respect to room type and object first ignited.

\section{Fire statistics}

The statistics used in this paper originates form the Swedish IDA database, provided by MSB [8] during twelve years (2000-2011). IDA is national and freely available database where all rescue service response is recorded. All rescue services in Sweden reports to this database. To be able to compare and identify differences between arson and accidental fires two cases have been studied (see table 2).

Table 2. Numbers and type of fires.

\begin{tabular}{|l|c|}
\hline \multicolumn{1}{|c|}{ Case } & Number of fires \\
\hline All fires & 2965 \\
\hline All fires except arson & 2365 \\
\hline
\end{tabular}

Approximately 95\% of the fires in each case have been categorized with respect to the room of fire origin. An example of this categorization is presented in table 3.

Table 3. The eight most common room types of fire origin in commercial buildings.

\begin{tabular}{|l|c|c|}
\hline \multicolumn{1}{|c|}{ Room of fire origin } & Number of fires & Share of total \\
\hline Sales area & 846 & 0.28 \\
\hline Kitchen & 382 & 0.12 \\
\hline Other & 349 & 0.11 \\
\hline Outside building & 222 & 0.07 \\
\hline Storage & 165 & 0.05 \\
\hline Outside & 128 & 0.04 \\
\hline Staff area & 103 & 0.03 \\
\hline Loading dock & 72 & 0.02 \\
\hline
\end{tabular}

The categories “Outside” and “Outside building” represents the same type of fire origin, the reason for the two different labels is that the form that the rescue service fills in has been changed sometime during the data collection period. This means that the total share of fires outside building is 0.11 . 
The fires in each room of fire origin have then been categorized with respect to the object first ignited. An example of this categorization is presented in table 4.

Table 4. The eight most common objects first ignited in the sales area in commercial buildings.

\begin{tabular}{|l|c|c|c|}
\hline \multicolumn{1}{|c|}{ Object first ignited } & $\begin{array}{c}\text { Number } \\
\text { of fires }\end{array}$ & $\begin{array}{c}\text { Share of sales } \\
\text { area fires }\end{array}$ & $\begin{array}{c}\text { Share of } \\
\text { total }\end{array}$ \\
\hline Other & 171 & 0.20 & 0.06 \\
\hline Outside building & 24 & 0.03 & 0.01 \\
\hline Other electrical installations & 86 & 0.10 & 0.03 \\
\hline Stove & 16 & 0.02 & 0.01 \\
\hline Unknown & 75 & 0.09 & 0.02 \\
\hline Fluorescent batten & 97 & 0.11 & 0.03 \\
\hline Furnishing & 59 & 0.07 & 0.02 \\
\hline Paper/cardboard & 16 & 0.02 & 0.01 \\
\hline
\end{tabular}

A fire growth rate is assigned to each one of the objects first ignited and it can be weighted with its share of total fires.

\section{Fire growth rate}

A review of literature and experimental test reports have been conducted in order to find fire growth rates for the objects categorized in the statistics, also see Appendix A. The fire growth rate will depend on the material, size and configuration of the object, but the statistics do not reveal much in regard to this. This creates uncertainties when assigning deterministic alpha-values to each object. It would of course be desirable if a statistical distribution for the fire growth rate for each category could be created based on experimental data. However, a vast amount of experiments and data is needed in order to create such distributions and for most objects only a few data points are available. The alpha-values assigned to the objects in this study are mean values based on available literature and published experimental test reports. The entire list of alpha-values used in this study is available in Appendix A.

To obtain the distributions the assigned fire growth rates were divided into intervals of $0.003 \mathrm{~kW} / \mathrm{s}^{2}$ from 0 $0.192 \mathrm{~kW} / \mathrm{s}^{2}$. In each interval the mean value of the fire growth rate was assigned to the interval and the frequency of each fire growth rate was plotted in a histogram. To the histogram a lognormal distribution was fitted using MATLAB [24].

The expected value, $E(x)$, of a lognormal distribution is given by Eq. 2.

$E(x)=\exp \left(\mu+\frac{\sigma^{2}}{2}\right)$

Where $\mu$ is the mean and $\sigma$ is the standard deviation. The $\mathrm{X}^{\text {th }}$ percentile of a lognormal distribution provides a single parameter measure of the largest value that will occur in $\mathrm{X} \%$ of the cases and is given by Eq. 3 .

$x_{x^{\text {th }}}=\exp (\mu+A \sigma)$

where $A$ is a constant depending on what percentile is sought and can be found in tables for normal distributions. For the $95^{\text {th }}$ percentile $A=1.645$ and for the $99.5^{\text {th }}$ percentile $A=2.575$.

\section{RESULTS FOR COMMERCIAL BUILDINGS}

Table 5 shows the estimated lognormal distributions of the fire growth rate for commercial buildings in Sweden based on the statistical data and estimation of fire growth rates as described in the method section above. The distributions are divided into accidental fires where arson fires have not been included and into all fires where arson fires have been included into the statistical data. 
Table 5. Parameters for lognormal distributions and percentile values

\begin{tabular}{|c|c|c|c|c|c|c|}
\cline { 2 - 6 } \multicolumn{1}{c|}{} & $\begin{array}{c}\boldsymbol{\mu}_{\boldsymbol{\alpha}} \\
(\text { Std. Err.) }\end{array}$ & $\begin{array}{c}\boldsymbol{\sigma}_{\boldsymbol{\alpha}} \\
(\text { Std. Err.) }\end{array}$ & $\begin{array}{c}\mathbf{E}(\boldsymbol{\alpha}) \\
\left(\mathbf{k W} / \mathbf{s}^{\mathbf{2}}\right)\end{array}$ & $\begin{array}{c}\boldsymbol{\alpha}_{\mathbf{9 5}} \\
\left(\mathbf{k W} / \mathbf{s}^{\mathbf{2}}\right)\end{array}$ & $\begin{array}{c}\boldsymbol{\alpha}_{\mathbf{9 9 . 5}} \\
\left(\mathbf{k W} / \mathbf{s}^{\mathbf{2}}\right)\end{array}$ & $\begin{array}{c}\text { Percentile for } \boldsymbol{\alpha} \\
=\mathbf{0 . 0 4 7} \mathbf{~ k W} / \mathbf{s}^{2}\end{array}$ \\
\hline $\begin{array}{c}\text { Accidental fires } \\
\text { (arson excl.) }\end{array}$ & $\begin{array}{c}-5.091 \\
(0.023130)\end{array}$ & $\begin{array}{c}1.100 \\
(0.0163611)\end{array}$ & 0.011 & 0.038 & 0.105 & $97 \%$ \\
\hline $\begin{array}{c}\text { All fires (arson } \\
\text { incl.) }\end{array}$ & $\begin{array}{c}-4.727 \\
(0.024032)\end{array}$ & $\begin{array}{c}1.246 \\
(0.0169978)\end{array}$ & 0.019 & 0.069 & 0.219 & $91 \%$ \\
\hline
\end{tabular}

Figures 2 and 3 show the probability density function (PDF) and the cumulative distribution function (CDF) for the accidental fires and all fires respectively. The histograms shown in the figures display data sets using a probability histogram, i.e. the height of each rectangle is the fraction of data points that lie in the bin divided by the width of the bin [25]. This makes the sum of the areas equal to one.
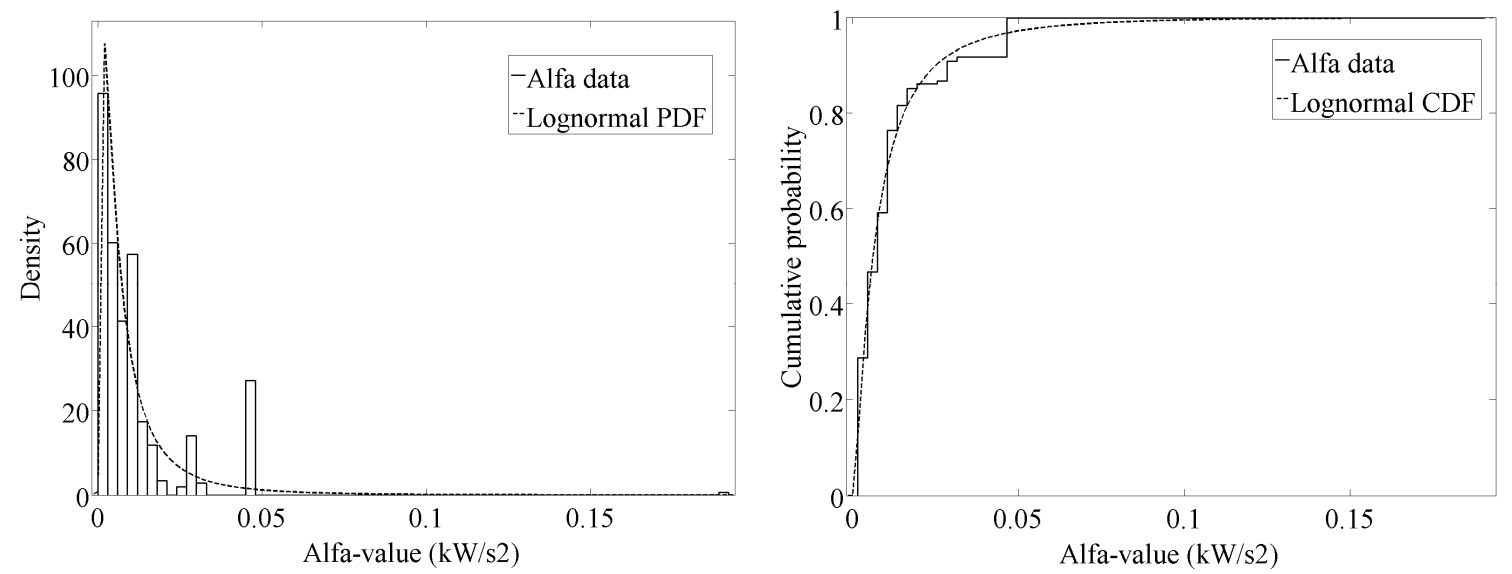

Fig. 2. Accidental fires (arson excluded), to the left: histogram and PDF for estimated lognormal distribution, to the right: CDF for the estimated lognormal distribution.
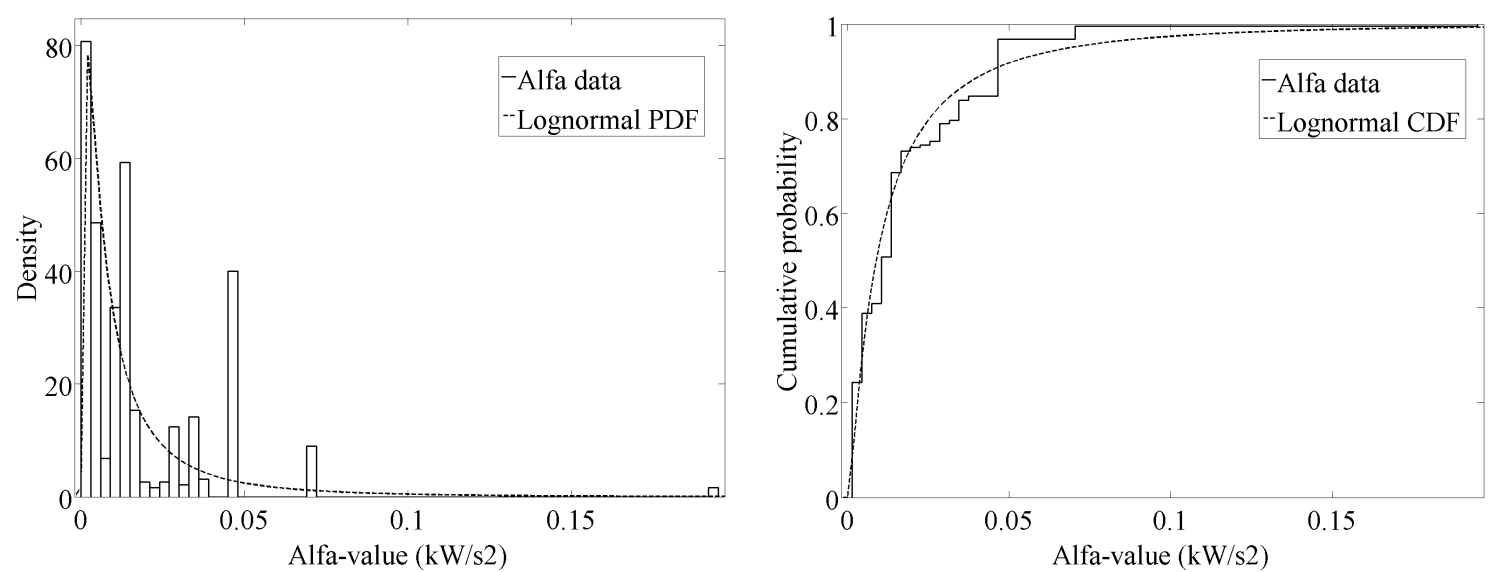

Fig. 3. All fires (arson included), to the left: histogram and PDF for estimated lognormal distribution, to the right: CDF for the estimated lognormal distribution.

The fitted curves show a difference between fire growth rates depending on whether arson is accounted for or not. If arson is not accounted for the expected value of the fire growth rate is $0.0113 \mathrm{~kW} / \mathrm{s}^{2}$ and if arson is accounted for the expected value is $0.0192 \mathrm{~kW} / \mathrm{s}^{2}$, i.e. a $70 \%$ higher fire growth rate when arson is accounted for. There is an even bigger difference when considering the tail of the distribution, for the $95^{\text {th }}$ percentile the fire growth rate is $83 \%$ higher and for the $99.5^{\text {th }}$ percentile the fire growth rate is $110 \%$ higher. It is concluded that considering arson increases the expected alpha-value as well as the tail of the distribution. In addition the distribution for the fire growth rates when considering arson has a higher 
standard deviation than when not considering arson, indicating that the uncertainties in the values are larger. Also it is shown in table 5 that if a fast [15] fire growth rate with an alpha-value of $0.047 \mathrm{~kW} / \mathrm{s}^{2}$ is used for design, $97 \%$ of all accidental fires are covered while as only $91 \%$ of all fires (including arson) is covered. In the figures above, there is a high density in the histograms around a fast fire growth rate of $0.047 \mathrm{~kW} / \mathrm{s}^{2}$, this is due to the discretization of determined alpha-values, also see the discussion section.

\section{DISCUSSION}

The approach where a fire growth rate is assigned to describe the HRR of a fire according to Eq. 1 is commonly used within fire safety engineering during design of buildings. Due to limited resources it is not possible to analyze more than a very limited amount of possible fire scenarios during the design phase of a building. Nevertheless, there is a need to evaluate a wide variety of objectives such as the ability to achieve protection objectives and life safety. In order to do such evaluations estimations of parameters like fire growth rate, fire location, maximum HRR, smoke production rate etc. is needed. In general a deterministic fire growth rate according to the worst credible case is often used. However, this type of deterministic analysis presents shortcomings, as discussed above and as concluded by Paté-Cornell [5], in the risk management phase since the fire risk is not quantified. The new method, presented in this paper, to develop a distribution of fire growth rates, presents one piece of the puzzle to further quantify the risk and estimate how conservative the chosen fire growth rate actually is for a specific building. Furthermore since the fire growth rate and the HRR are very important for life safety, i.e. using a non-representative fire growth rate results in other parameters such as smoke and gas production, radiation etc. being affected as well, the impact of the fire growth rate is therefore decisive. The new method is beneficial for practicing fire safety engineers, business owners, authorities etc., since the design fire can be quantified in terms of probability and therefore a concise design criterion can be stipulated, e.g. 95\% of all fires should be covered by the design.

As shown in the study for commercial buildings there is a considerable difference in fire growth rates at the higher percentile values if arson is included into the data, e.g. the $95^{\text {th }}$ percentile value including arson is $0.069 \mathrm{~kW} / \mathrm{s}^{2}$ and if arson is not included it is $0.038 \mathrm{~kW} / \mathrm{s}^{2}$. Both the Swedish and the New Zealand building codes have stipulated fire growth rates for the pre-flashover fire and for the considered commercial buildings both countries have chosen a fast fire growth rate of $0.047 \mathrm{~kW} / \mathrm{s}^{2}[3,4]$. According to the results for commercial buildings a fire growth rate of $0.047 \mathrm{~kW} / \mathrm{s}^{2}$ incorporates $97 \%$ of the accidental fire growth rates (excluding arson) and 91\% if arson is included. If designing for the fire growth rate stipulated by these codes $[3,4]$ the estimation of the fire growth rates, shown in table 5 , results in $9 \%$ of all fires being expected to actually grow faster than the design value (when arson is included). If the building type considered has a large percentage of arson fires there is clearly a need to take this into account during the design phase due to the relatively large difference in anticipated fire growth rates. In most cases a faster fire growth rate would result in a shorter time to reach tenability conditions. If the building in question's fire protection is optimized and designed for a specific fire growth rate, e.g. a growth rate stipulated by code, an actual fire having a faster fire growth rate, than designed for, would result in people getting exposed to untenable conditions during evacuation. However, to our opinion most buildings are not that optimized and it should also be noted that the tenability conditions, as stipulated by building codes, are not lethal conditions, i.e. there are a variety of safety margins built into the code. But excluding arson during design will decrease the safety margin and expose people to a higher risk than if arson was accounted for during design. Faster fire growth rates will of course affect other protection objectives as well, e.g. protection of functions in multifunctional buildings, where the location and size of the fire is of great importance [14]. The design fire growth rate will have an impact on the overall fire safety level, both life safety as well as other protection objectives such as property, functions and businesses. Furthermore there is a clear trend, shown in Fig. 2 and 3, that accounting for arson fires results in a higher fire growth rate. Hence it is important to take arson into account if a large percentage of the expected fires are likely to be arson fires.

The presented method combines two different data sources, data regarding fire growth rates for specific objects and statistical data of occurred fires. There are uncertainties connected to both data types. For the fire growth rates there are problems with finding values for different starting objects, there might not be any data at all available and experiments are needed or gross estimations have to be made. Furthermore there are also problems with the very broad categories used in the statistics, e.g. if the first ignited object is a sofa and an alpha-value is needed for the category sofa, there can be a large variation of growth rates 
between different tests and sofas, see e.g. Fig. 4. One way to handle this would be to describe every first ignited object's fire growth rate with a distribution. However, the available data is fairly limited for most objects and it would be very difficult to do and at the same time new uncertainties would be introduced. A problem with the case study for commercial buildings is the large number of "unknown" and "other" first objects ignited. For these objects a weighted average value has been used which creates an uncertainty. The weighted average value is probably not the accurate alpha-value for these categories and if e.g. more arson fires are present in these groups the alpha-value would be higher than estimated in the study. This is attributed to shortcomings in the statistics and improving the statistics would reduce this uncertainty. When using this method for retrieving alpha-values for building design purpose it is therefore recommended to conduct a sensitivity analysis of the effect of these "unknown" and "other" first objects ignited. It is believed that there is a tendency to categorize arson fires as unknown in a higher degree than other fires due to categorizing the fire as arson may have legal implications. If this is the case the effect on the result of the case study would be that the fire growth rate including arson is underestimated.

Another problem with alpha-values is whether the fire really is well described by an alpha- $\mathrm{t}^{2}$ fire. If looking at the HRR curves in Fig. 4 there is the matter to decide on what is the alpha-value for each single object. In addition the alpha- $\mathrm{t}^{2}$ fire might not at all describe the actual HRR, this is especially evident for sofa Y5.4/15 in Fig. 4. However it should be pointed out that exactly describing how a fire develops in reality is not the same as designing a building. As long as the design fire covers the worst credible fire, the design fire is probably acceptable to design for, as it covers most other fires. In Fig. 4 the design fire probably covers most of the sofa fires in the figure. Another issue with determining fire growth rates for starting objects is that the values are most often taken from furniture calorimeter tests, hence they are free burning and the room effects on the fire development is ignored [1]. For small rooms, in relation to the HRR, this can be of importance since the radiation from the smoke layer might increase the mass loss rate hence accelerate the fire. However this effect is assumed to be quite small in the early stage of the fire for the buildings studied where most areas are large open spaces reducing this effect.

As the fire spreads to additional objects within the room the total fire growth rate in the compartment might increase. This means that using one single alpha-value in a design could be non-conservative if it could be expected that the fire spreads to other objects than the first object ignited. The fire growth rate, after the fire starts to spread to other objects, will depend on several parameters like: distribution of combustibles, type of combustibles, compartment layout, compartment height etc. Thus, the presented distribution in this paper gives an estimate of the distribution of the initial fire. Within the statistics the first object ignited is sometimes a small item with a low growth rate, e.g. a light bulb. The low growth rate is believed to be valid due to the fact that in order to be able to determine the actual ignition source to be the light bulb the damage by the fire would be rather small indicating a low growth rate. However, the same method could be used to arrive at a distribution of the fire growth rate for a longer time period if data on room growth rates are used instead of single objects.

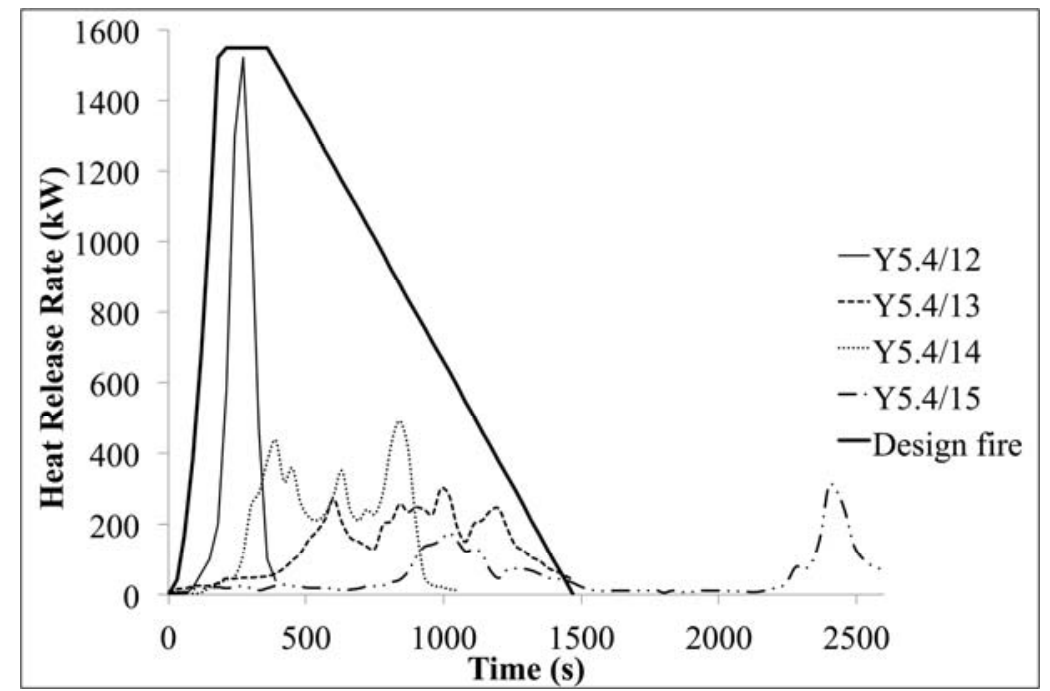

Fig. 4. HRR curves for different sofas reproduced from Särdqvist [16] and a suggested possible design fire. 
When comparing the histograms to the estimated distributions and the fitted PDF:s, see Fig. 2 and 3, it is shown that there are deviations between the distributions and the data for the alpha-values. This is especially evident at $0.047 \mathrm{~kW} / \mathrm{s}^{2}$ and $0.07 \mathrm{~kW} / \mathrm{s}^{2}$. One explanation for this deviation is that discrete intervals and estimations have been made for each first ignited object. These estimations have then been used for all fires where the first ignited object is the same, resulting in the fact that there are a large number of "observations" at specific values. In reality the distribution is more continuous which would result in lower densities at e.g. $0.047 \mathrm{~kW} / \mathrm{s}^{2}$ making the fitted log-normal distribution more accurate. Also the adherence to the standard alpha-values, see e.g. [15], results in the fact that a large number of "observations" is shown at these specific values. If a distribution was used for the fire growth rates of the first objects ignited the distribution of the overall fire growth rate would have been more continuous, however such data is not available.

Another difficulty with the fire growth rates for the arson fires is that the effect on the growth rate when igniting other combustibles using an accelerant is not studied well. Richards [17] e.g. studied the HRR from a Molotov cocktail, however the ignition of secondary items was not studied well. Janssens et al [18] studied the effect of ignition of furniture with an accelerant, however only a small amount of flammable liquid was used, 59-118 ml, and the conclusion was that ignition with the large gas burner resulted in the same HRR considering uncertainties. The amount of flammable liquid used in the study by Janssens et al [18] is not considered to cover arson fires since a larger amount of flammable liquid is expected, around 1 L. Krüger et al [19] used approximately $1 \mathrm{~L}$ of flammable liquids resulting in a fire growth rate of approximately $0.07 \mathrm{~kW} / \mathrm{s}^{2}$, the same fire growth rate as Holborn et al [10] used. In this study $0.07 \mathrm{~kW} / \mathrm{s}^{2}$ has been used since it is judged reasonable considering the time frame and amount of flammable liquids, also see Appendix A. However, there are considerable uncertainties and there is a need for further research within this area.

There are also uncertainties associated with the fire statistics, which is used as the second data source. Several countries presents fire statistics yearly and in many cases it is possible to distinguish the distribution of objects first ignited in different occupancies. In this paper Swedish fire statistics are used which means that the distribution of fire growth rates presented is primarily valid for Sweden. It is mandatory for all rescue services in Sweden to fill in a special form after every emergency turn-out. Data from these forms are collected and compiled by the Swedish Civil Contingencies Agency in a public database, which holds information on more than 160,000 fires in buildings. Even though there is a lot of data it still has its limitations. Firstly, the data is collected with a special form consisting mainly of tick boxes with different alternatives, this means that there is a control of the type of data that is collected and it can lead to interesting facts not being collected. Secondly, there might be some inconsistency in the filling of the forms since they are filled in by a variety of people within the rescue service organisation. Finally, the categories unknown cause and unknown first object ignited are often very large which will hold some hidden statistics that can be important. This is an uncertainty and in this paper the unknown cause and first object ignited has been assumed to have a fire growth rate distributed according to the known first objects ignited. However, this does not affect the method itself.

As can be seen in Fig. 2 and 3 the distribution for fire growth rates follows a log-normal distribution fairly well which is supported by other studies, see e.g. [10]. When taking into account arson fires in the distribution both the expected value and the percentile values increases. There are considerable differences when studying higher percentile values due to the tail of the distribution and that the standard deviation is larger for the distribution with arson fires. In the statistical data approximately $20 \%$ of the fires are reported as arson and this large percentage is of course affecting the result. In buildings where arson fires are less common the difference would probably not be as large, however this is dependent upon the type of arson fire. In the data the main reason for arriving at high alpha-values is the flammable liquid fires, which constitutes approximately $10 \%$ of all arson fires, i.e. approximately $2 \%$ of all fires. This affects the estimated growth rates of the fires that are unknown as well, which is a reasonable assumption due to the fact that there statistically should be some arson fires that are unknown. Another factor is that the arson fires often are started in areas where the growth rate is assumed to be high, e.g. approximately $25 \%$ of the arson fires are external fire where a "fast" growth rate is assumed.

The lognormal distribution is intuitive for the fire growth rate and this was also concluded by Holborn et al [10]. The study has been carried out for Swedish commercial buildings. The difference between countries is mainly expected to be due to the fire statistics, here the largest difference between countries are expected. 
When comparing the results shown in table 5 with another similar study made by Holborn et al [10] they show similar results, see results from [10] in table 1. It should be noted that the values presented by Holborn et al are based on a small number of observations, however every observation is more detailed since a fire investigator attended every observed fire [10]. Therefore, it is not surprising that the standard deviation is larger for the values given by Holborn et al [10]. Further it is unknown whether arson fires are included or not and it is difficult to determine what category (public building or retail) that corresponds to the Swedish commercial building. However, it can be seen that the values are pretty similar and the values obtained in this paper is somewhere in between Holborn's public and retail values for most part. Also the values obtained with the new method are similar to the values presented by both Nystedt [11] and Angerd and Frantzich [13] supporting its validity.

\section{CONCLUSIONS}

A new method for determining a distribution of fire growth rates for different buildings have been developed and is based on fire growth rates for first objects ignited and fire statistics regarding what kind of first objects are ignited. The method fills a gap in the current methods in determining fire growth rates since it provides a way to quantify the severity of the chosen fire growth rate, e.g. the $95^{\text {th }}$ percentile fire growth rate. It has been shown that, if arson is included when determining the distribution, a considerably higher fire growth rate is obtained, especially for the tail of the distribution. If the probability for arson fires is considerable for the specific building (considering statistics for the area, building type etc.), a higher fire growth rate is expected and this might need to be taken into account during design since it affects the overall fire safety level of the building.

There are uncertainties connected with the obtained values for the commercial buildings, however the method itself produces values that are supported by the literature and improvements in statistics (e.g. reducing the amount of unknown first objects ignited) and values of fire growth rates will make the method even more usable. Furthermore the method provides a mean to quantify the fire risk and associated uncertainties in a better way than with just a prescribed fire growth rate to be used for design.

In order to limit the uncertainties more research is needed regarding the effect on the fire growth rate on ignition of secondary objects ignited with flammable liquids. Further, improving the statistics by reducing categories such as "unknown" and "other" would make the results even more reliable and there is a need for development of the way of recording data from the rescue service operations.

\section{REFERENCES}

[1] Karlsson B., and Quintiere J.G., Enclosure fire dynamics. CRC Press, New York, 2000.

[2] Babrauskas V., and Peacock R.D., Heat release rate: the single most important variable in fire hazard, Fire Safety Journal, 1992; 18(3): 255-272, http://dx.doi.org/10.1016/03797112(92)90019-9

[3] Department of Building and Housing, C/VM2 Verification Method: Framework for Fire Safety Design - For New Zealand Building Code Clauses C1-C6 Protection from Fire, Department of Building and Housing, Wellington, New Zealand, 2012.

[4] Boverket. Boverkets allmänna råd om analytisk dimensionering av byggnaders brandskydd - BFS 2011:27, BBRAD 1 [Boverket's regulations regarding performance-based fire safety design in buildings - BFS 2011:27, BBRAD 1], Boverket, Karlskrona, Sweden, 2011.

[5] Paté-Cornell ME. Uncertainties in risk analysis: Six levels of treatment. Reliability Engineering \& System Safety. 1996; 54(2): 95-111, http://dx.doi.org/10.1016/S0951-8320(96)00067-1

[6] Proulx G., “Evacuation time”. In: DiNenno PJ, Drysdale D, Beyler CL, Walton WD, Custer RLP, Hall JR, and Watts JM, editor(S). SFPE handbook of fire protection engineering $4^{\text {th }} \mathrm{ed}$, National Fire Protection Association, Quincy, MA 2008, p. 3-355 - 3-372.

[7] Department for Communities and Local Government, Fire Statistics Great Britain, 2010 - 2011, ISBN 978-1-4098-3235-5, Department for Communities and Local Government, London, UK, 2011. 
[8] Myndigheten för samhällsskydd och beredskap [Swedish Civil Contingencies Agency]. Informationssystemet IDA [Information system IDA], 2012.

[9] Klason L-G., Andersson P., Johansson N., and van Hees P., Design Fires for Fire Protection Engineering of Swedish School Buildings. In: Fire and Materials: Proceedings of the 12th International Conference and Exhibition, San Francisco, USA, 31 January - 2 February 2011, pp. 159-170, London, Interscience Communications Limited.

[10] Holborn P.G., Nolan P.F., and Golt J., An analysis of fire sizes, fire growth rates and times between events using data from fire investigations, Fire Safety Journal, 2004; 39(6): 481-524, http://dx.doi.org/10.1016/j.firesaf.2004.05.002

[11] Nystedt F., Verifying Fire Safety Design in Sprinklered Buildings, Report from Department of Fire Safety Engineering and Systems Safety, Report no 3150, Lund University, Sweden, 2011.

[12] Sundström B., Fire Safety of Upholstered Furniture - the final report on the CBUF research programme. Report for European Commission Measurement and testing, Report EUR 16477 EN, Interscience Communications Limited, London, UK, 1995.

[13] Angerd M., and Frantzich H., The use of uncertainty analysis in performance based design. In: Proceedings of the 4th International Conference on Performance-Based Codes and Fire Safety Design Methods, Melbourne, Australia, 20-22 March 2002, pp. 179-189, Bethesda, USA, Society of Fire Protection Engineers.

[14] Nilsson M., Frantzich H., and van Hees P., Selection and evaluation of fire related scenarios in multifunctional buildings considering antagonistic attacks, Fire Science Reviews, 2013; 2(3): 1-20, http://dx.doi.org/10.1186/2193-0414-2-3

[15] NFPA., NFPA 92B - Standard for Smoke Management Systems in Malls, Atria, and Large Spaces, 2009 Edition, Quincy, MA, USA, National Fire Protection Association, 2009.

[16] Särdqvist S., Initial fires: RHR, smoke production and CO generation from single items and room fire tests. Report from Department of Fire Safety Engineering, Lund University, Sweden, 1993.

[17] Richards P.L.E., Characterising a design fire for a deliberately lit fire scenario, MEFE Thesis, University of Canterbury, New Zealand, 2008.

[18] Janssens M.L., Gomez C., Huczek J.P., et al., Reducing Uncertainty of Quantifying the Burning Rate of Upholstered Furniture, SwRI Project No. 01.15998, Southwest Research Institute, San Antonio, TX, USA, 2012.

[19] Krüger, S., Deubel, J., Werrel M., et al., Experimental Studies on the Effect of Fire Accelerant During Living Room Fires. In: Conference proceedings, Fire and Materials 2013, 13th International Conference and Exhibition, San Francisco, USA, 28-30 January 2013, pp. 729-741, London, UK, Interscience Communications Limited.

[20] Angerd, M,. Är utrymningsschablonerna vid brandteknisk dimensionering säkra? - En osäkerhetsanalys av utrymningssäkerheten i affärer dimensionerade enligt NR 1988 [Are the prescriptive evacuation rules safe? - Uncertainty analysis of life safety in shops designed according to NR 1988], Report from Department of Fire Safety Engineering, Report no 5028, Lund University, Sweden, 1999.

[21] Peacock, R.D., Reneke, P.A., Averill, J.D., et al., Fire Safety of Passenger Trains; Phase II: Application of Fire Hazard Analysis Techniques, National Institute of Standards and Technology Report NISTIR 6525, Gaithersburg, MD, USA, 2002.

[22] Nystedt, F., and Frantzich, H., Kvalitetsmanual för brandtekniska analyser vid svenska kärntekniska anläggningar [Quality manual for fire safety analyses at Swedish nuclear power plants], Report from Department of Fire Safety Engineering and Systems Safety, Report no 3160, Lund University, Sweden, 2011. 

National Fire Protection Association, Quincy, MA 2008, p. 3-1 - 3-59.

MATLAB (Version: R2012b (8.0.0.783)) [computer program], The MathWorks, Inc, USA, 2013.

[25] MathWorks, MATLAB, Statistics Toolbox - User's Guide, R2013a, The MathWorks, Inc., USA, 2013.

\section{APPENDIX A - FIRE GROWTH RATES}

Table A1 below shows the chosen fire growth rates for the object first ignited that were common for all room types. The values are based on literature review and judgment by the authors. Based on gathered data in the literature review a fire growth rate was chosen for every single object. The values were chosen to represent the expected value for each object.

Table A1. Assigned alpha-values for first objects in all room types.

\begin{tabular}{|l|c|c|}
\hline \multicolumn{1}{|c|}{ Object first ignited } & $\boldsymbol{\alpha}\left(\mathbf{k W} / \mathbf{s}^{\mathbf{2}}\right)$ & References as basis for choice of $\boldsymbol{\alpha}$ \\
\hline Exterior fire & 0.047 & {$[9,15,16]$} \\
\hline Other electrical installations & 0.009 & {$[10]$} \\
\hline Stove & 0.0029 & {$[10,20]$} \\
\hline Fluorescent lamp & 0.005 & {$[10]$} \\
\hline Paper/carton & 0.002 & {$[16,21]$} \\
\hline Fan/HVAC & 0.0009 & - \\
\hline Trash in container & 0.015 & {$[16,21]$} \\
\hline Flammable liquid & 0.07 & {$[10,19]$} \\
\hline Heating equipment & 0.0009 & - \\
\hline Refrigerator & 0.0029 & {$[20]$} \\
\hline Switchgear room & 0.0009 & {$[22]$} \\
\hline Light bulb & 0.005 & {$[10]$} \\
\hline Machine & 0.0009 & - \\
\hline Car & 0.017 & {$[16,23]$} \\
\hline Transformer & 0.0009 & {$[22]$} \\
\hline
\end{tabular}

${ }^{a}$ This value was chosen for all flammable liquid fires except them in large storage areas where $0.19 \mathrm{~kW} / \mathrm{s}^{2}$ was chosen due to the expected fire growth rate in rack storage ignited with flammable liquids.

Exterior fires can vary considerably as discussed in [9] and they are often arson fires. However, due to the statistics it is assumed that when an exterior fire is indicated there was no flammable liquid used since flammable liquids is a separate category. This removes the high end of the growth rates for exterior fires and common first objects ignited are assumed to be idle pallets, trash, vehicle etc. Based on the references in the table a growth rate of $0.047 \mathrm{~kW} / \mathrm{s}^{2}$ was chosen.

Paper and carton is a fairly undefined category, the above value is based upon paper in waste baskets from [16] and trash bags from [21]. Trash in container was chosen based on the same references, however plastic commodities was included as well, hence the higher fire growth rate.

For switchgear rooms a recommended value from [22] has been used. This is also considered to represent transformer rooms since most transformers in these public buildings are dry-type transformers in Sweden. Other electrical installations have a wider spectrum and the value has been chosen according to [10]. Further the heating equipment is most often public district heating with limited amount of combustible material in technical areas, hence heating equipment was given a value in the same order as electrical rooms. In typical HVAC rooms the amount of combustible material is limited and considered equivalent to electrical rooms. Machine is also a quite undefined object and it was chosen equivalent to electrical equipment due to the fact that most expected machines in this type of occupancies are of electrical type. It should also be noted that the object machine was only the first object ignited in approximately $1 \%$ of the observed fires, hence the impact of the chosen value is limited. 
Flammable liquids have a very fast fire growth rate. The use of flammable liquids in an arson fire is often of the type where the arsonist brings flammable liquids to start a fire. Hence the amount of flammable liquids is generally limited and in this study assumed to be around $1 \mathrm{~L}$ in average. When pouring out flammable liquid on other combustibles it is expected that the flammable liquid will burn off fairly quickly, but also increase the fire growth rate of the ignited object. Hence a fire growth rate that is faster than regular combustibles but slower than just flammable liquids is reasonable considering the studied time frame. The value presented by [10] is used which is also supported by the test performed by Krüger et al [19] showing a similar fire growth rate for a room where the fire was started with approximately $1 \mathrm{~L}$ of flammable liquids in the different tests.

The chosen value for car is a mean value of the fire growth rates presented in [23] and [16].

Below in table A2 are the values for the objects label: "other”, “ unknown”, "Furnishing and decorations” and "other furnishing and decorations" dependent on specific room types presented. The "other" and "unknown" categories have values that are weighted average values. For "furnishing and decorations" and "other furnishing and decorations" representative values have been chosen based upon the assumed type of combustibles present in the specific room type. The values were chosen to be according to the standard values for fire growth rates, see e.g. [15], either slow, medium, fast, ultra fast or in the middle between the categories were chosen.

Sales area for example was assumed to consist of clothing store, food store, electronic store, flower store and furniture store. Based on curves in [23] clothing store was assumed to have a growth rate of 0.049 $\mathrm{kW} / \mathrm{s}^{2}$ based on clothing fires, food store $0.03 \mathrm{~kW} / \mathrm{s}^{2}$ based on solid pile storage of FM class $3 \& 4$ material, electronic store $0.013 \mathrm{~kW} / \mathrm{s}^{2}$ based on a tv-set, $0.012 \mathrm{~kW} / \mathrm{s}^{2}$ for flower store based on judgment, 0.050 $\mathrm{kW} / \mathrm{s}^{2}$ for furniture store based on furniture data. The average value was calculated and found to be 0.031 $\mathrm{kW} / \mathrm{s}^{2}$ and the closest category, $0.030 \mathrm{~kW} / \mathrm{s}^{2}$ (between medium and fast), was chosen. The same procedure was followed for the other room types, except for the category "other". For the column "other" and "unknown" with respect to the row sales area, the probability (observed fraction of fires) of ignition of each first object ignited was multiplied by the assigned alpha-value for that object. The sum of all those values represents the weighted average value for the categories "other" and "unknown”. In the obtained weighted average values the categories "other" and "unknown" was included as well, this means that it was an iterative process obtaining the values, which was done in Excel. 
Table A2. Alpha-values for imprecise first objects for the different room types

\begin{tabular}{|c|c|c|c|}
\hline \multirow{3}{*}{ Room type } & \multicolumn{3}{|c|}{ Object first ignited } \\
\hline & \multicolumn{2}{|c|}{$\begin{array}{c}\text { "Other" and "unknown" } \\
\text { (weighted average value) }\left(\mathrm{kW} / \mathrm{s}^{2}\right)\end{array}$} & \multirow{2}{*}{$\begin{array}{c}\text { "Furnishing and decorations" } \\
\text { and "other furnishing and } \\
\text { decorations" }\left(\mathrm{kW} / \mathrm{s}^{2}\right)\end{array}$} \\
\hline & Incl. arson & Excl. arson & \\
\hline Sales area & 0.0150 & 0.00860 & 0.0295 \\
\hline Kitchen & 0.00399 & 0.00372 & 0.012 \\
\hline Other $^{\mathrm{a}}$ & 0.0150 & 0.0110 & $\begin{array}{l}0.0150 \text { (incl. arson) } \\
0.0110 \text { (excl. arson) }\end{array}$ \\
\hline Outside the building & 0.0346 & 0.0286 & 0.047 \\
\hline Large storage area & 0.0333 & 0.0141 & 0.19 \\
\hline Outside & 0.0364 & 0.0323 & 0.047 \\
\hline Staff area & 0.00781 & 0.00609 & 0.012 \\
\hline Loading dock & 0.0255 & 0.0202 & 0.047 \\
\hline Office & 0.00883 & 0.00544 & 0.012 \\
\hline HVAC area & 0.00281 & 0.00285 & No observed fires \\
\hline Electrical appliances room & 0.00803 & 0.00787 & No observed fires \\
\hline Small storage room & 0.0232 & 0.00878 & 0.047 \\
\hline Separate small building & 0.0308 & 0.0241 & 0.047 \\
\hline Unknown & 0.047 & 0.047 & 0.047 \\
\hline Basement & 0.0208 & 0.0171 & 0.047 \\
\hline Production area & 0.00950 & 0.00658 & 0.047 \\
\hline Switchgear room & 0.0029 & 0.0029 & No observed fires \\
\hline Parking garage & 0.00996 & 0.0104 & 0.012 \\
\hline Assembly hall & 0.0142 & 0.0125 & 0.0295 \\
\hline Boiler room & 0.00373 & 0.00113 & No observed fires \\
\hline Garbage chute & 0.0176 & 0.0167 & 0.047 \\
\hline Staircase & 0.0117 & 0.00722 & 0.012 \\
\hline Attic & 0.0199 & 0.0181 & 0.047 \\
\hline Toilet & 0.00466 & $\begin{array}{c}\text { Not enough } \\
\text { observed fires }\end{array}$ & 0.012 \\
\hline Workshop & 0.0171 & 0.00772 & 0.012 \\
\hline Corridor & 0.00904 & $\begin{array}{c}\text { Not enough } \\
\text { observed fires }\end{array}$ & 0.012 \\
\hline
\end{tabular}

${ }^{a}$ Due to the fact that the category other is very imprecise it was chosen to just use the average value for both categories (the columns "other and unknown" and "furnishing and decorations and other furnishing and decorations”). 